\title{
A AUTO-ORGANIZAÇÃO INFANTIL COMO POTENCIALIDADE PARA A FORMAÇÃO HUMANA ${ }^{1}$
}

\author{
Júlia Boemer ${ }^{2}$ \\ Soraya Franzoni Conde ${ }^{3}$
}

\begin{abstract}
RESUMO
Este artigo aborda as potencialidades de auto-organização no processo formativo das crianças estudantes da Escola Itinerante Caminhos do Saber, do Movimento dos Trabalhadores Rurais Sem Terra- MST. A escola localiza-se no acampamento Maila Sabrina, no estado do Paraná, e fundamentase nos princípios teóricos e práticos da Pedagogia Soviética. Realizamos estudos bibliográficos e de documentos da escola; entrevistas semiestruturadas com crianças, estudantes, professoras e coordenação pedagógica; participação nos Núcleos Setoriais, em reuniões e observações diretas em sala de aula. Concluímos que as crianças e os demais estudantes pesquisados ainda não se autoorganizam, mas aprendem e desenvolvem habilidades, comportamentos, valores e hábitos de organização fundamentados em princípios socialistas.
\end{abstract}

Palavras-chave: Infância; Ensino Fundamental; Pedagogia Soviética; Auto-organização.

\begin{abstract}
This article discusses the potential of the self-organization of children in the Campaigning School of the Landless Workers Movement (MST), considering the elements of the organization of pedagogical practice that contribute to this development. School located in the Maila Sabrina seminary, in the state of Paraná, and is based on the theoretical-practical principles of Soviet pedagogy. We select the category of analysis as self-organization, because we understand the basis of the emancipatory pedagogical process. We carry out bibliographic studies and school documents; semi-structured interviews with children, students, teachers; participation in the Sectoral Centers and in the meetings; support groups. We conclude that children still do not self-organize, but learn to develop skills, behaviors, values and habits of organization, based on socialist principles.
\end{abstract}

Keywords: Childhood; Elementary Education; Soviet Pedagogy; Self-organization.

\footnotetext{
${ }^{1}$ Este artigo parte de nossa pesquisa de Mestrado, cuja dissertação intitula-se "Contribuições da Escola Itinerante Caminhos do Saber para a auto-organização das crianças: fundamentos da Pedagogia Soviética", 2018 e contou com apoio e financiamento da Coordenação de Aperfeiçoamento de Pessoal de Nível Superior e (CAPES/MEC) e da Fundação de Amparo à Pesquisa de Santa Catarina (FAPESC).

${ }^{2}$ Mestra em Educação e Pedagoga pela Universidade Federal de Santa Catarina, E-mail: juliaboemer89@gmail.com

${ }^{3}$ Doutora em Educação, professora do Departamento de Estudos Especializados em Educação da UFSC. Atualmente, é coordenadora do curso de Pós-Graduação em Educação da referida instituição, coordenadora do Grupo de Estudos Trabalho, Educação e Infância e vice-líder do Núcleo de Estudos sobre as Transformações no Mundo do Trabalho. E-mail: sorayafconde@gmail.com
} 


\section{INTRODUÇÃO}

A contribuição da educação no processo de transformação social é assunto polêmico e debatido desde o início da industrialização e do desenvolvimento do capitalismo por pensadores conservadores, liberais e marxistas. De acordo com Meszáros (2005, p.198), a transformação social não se fará a partir da educação, mas sobretudo com ela, e, para que isso ocorra, é "necessário romper com a lógica do capital", pois se a educação não é o agente principal de qualquer transformação, nenhuma sociedade sobrevive sem um sistema educacional correspondente.

O referido autor defende uma educação que se lance para além do estágio atual de desenvolvimento das forças produtivas, capaz de contribuir para a emancipação da classe trabalhadora. Para isso, aponta como necessidade urgente a formulação de novos "processos de internalização". Em suas palavras, "necessitamos, urgentemente de uma atividade de 'contra-internalização' coerentemente sustentada, que não se esgote na negação [...] e que defina seus objetivos fundamentais, como a criação de uma alternativa abrangente concretamente sustentável ao que já existe" (MESZÁROS, 2005, p. 56).

Trata-se de incorporar uma nova cultura política para romper com a lógica da educação para o capital, que reforça e propaga os ideários que sustentam a ideologia capitalista à medida que esta fomenta as competências individuais, a competitividade, a meritocracia, ou seja, que promove a incorporação inconsciente dos padrões, práticas e valores que refletem a necessidade de reprodução e de crença no sistema. Nesse sentido, a escola pode contribuir com o rompimento das aparências e da desnaturalização dos problemas e dos conflitos sociais internalizados como naturais, eternos e evidentes.

Diante disso, apresentamos brevemente os resultados de nossa pesquisa de mestrado, a qual foi realizada durante os anos de 2017 e 2018 na Escola Itinerante Caminhos do Saber ${ }^{4}$, do Movimento dos Trabalhadores Rurais Sem Terra-MST. A escola localiza-se no acampamento Maila Sabrina, no estado do Paraná. Como procedimentos metodológicos, realizamos: estudo bibliográfico e de documentos orientadores da escola; entrevistas semiestruturadas com crianças e outros estudantes, professoras e coordenação pedagógica; participação nos Núcleos Setoriais (espaço destinado ao desenvolvimento da auto-organização

\footnotetext{
${ }^{4}$ Escolas Itinerantes são instituições criadas nos acampamentos da Reforma Agrária para atender os sujeitos crianças, jovens e adultos - enquanto estão na luta pela terra. Em 1996 foi reconhecida legalmente como experiência pedagógica no estado do Rio Grande do Sul. Foi desenvolvida em mais cinco estados brasileiros (Paraná, Santa Catarina, Goiás, Alagoas e Piauí). Atualmente, só existem Escolas Itinerantes no estado do Paraná, as quais funcionam em parceria com a Secretaria de Estado da Educação do Paraná (SEED/PR) e Associação de Cooperação Agrícola e Reforma Agrária do Paraná (ACAP) (CAMINI, 2011).
} 
estudantil), na Reunião da Comissão Executiva (espaço em que os estudantes, juntamente com a equipe pedagógica, avaliam e encaminham atividades cotidianas da escola) e na Reunião de Formação dos(as) Professores(as); acompanhamento de duas turmas dos Anos Iniciais do Ensino Fundamental ( $2^{\circ}$ e $5^{\circ}$ ano).

Este texto está organizado em quatro partes. Na primeira, apresentamos a constituição da identidade da criança Sem Terra forjada na luta de um movimento social a partir dos estudos socialistas, da teoria histórico-cultural e de observações da pesquisa de campo. $\mathrm{Na}$ segunda, apresentamos o estudo, a brincadeira e a forma como as crianças se relacionam com os adultos na escola como um elemento fundamental da auto-organização e engajamento infantil nas questões cotidianas. Em seguida, mostramos como a participação infantil na escola traça caminhos para a formação socialista das crianças. Por último, nas considerações finais, enfatizamos como a forma e o conteúdo escolar se articulam para forjar a formação humana do novo ser humano.

Embora, a auto-organização infantil ainda não ocorra, é possível afirmar que ocorre uma aprendizagem de novas habilidades, comportamentos, valores e hábitos, fundamentados em princípios socialistas. Nesse sentido, a escola torna-se um espaço potencializador para o desenvolvimento da auto-organização.

\section{1. "NA LUTA": IDENTIDADE DA CRIANÇA ESTUDANTE SEM TERRINHA}

De acordo com Leontiev (1978), cada geração inicia sua vida relacionando-se com os objetos e fenômenos criados pelas gerações anteriores. Estas, possuem condições específicas de vida que determinam o conteúdo da atividade que possa ser desenvolvida: "Ela apropria-se das riquezas deste mundo participando no trabalho, na produção e nas diversas formas de atividade social, desenvolvendo assim as aptidões especificamente humanas que se cristalizaram, encarnaram nesse mundo" (LEONTIEV, 1978, p. 3). Daí a importância da linguagem como forma de transmissão do conhecimento, já que é impossível construir todos os conhecimentos necessários para interagir com o mundo sem a mediação das gerações anteriores. Em outras palavras, a criança que nasce se apropria dos signos, instrumentos, fenômenos e se relaciona com o mundo, tornando-se um ser social a partir da mediação do adulto e das outras crianças. Esse processo de humanização é também o processo de

\footnotetext{
${ }^{5}$ Fala das crianças das turmas observadas e dos demais estudantes coordenadores dos Núcleos Setoriais, ao responderem a chamada (Diário de campo, março de 2018).
} 
educação, no qual as novas gerações se apropriam dos objetos da cultura e aprendem a utilizálos de acordo com suas funções sociais.

Nesse sentido, quando refletimos sobre a identidade da criança Sem Terra, vemos que essa infância é composta por brincadeira, estudo, disciplina, luta, desenvolvimento de diferentes habilidades, trabalho, organização, coletividade, entre outros elementos.

Segundo Nosella (2002, p. 114), “A criança é uma realidade original, mas não é uma ilha, nem um anjo descido do céu, menos ainda uma pura massa de instintos animais que devemos dobrar e adaptar ao ambiente". O lugar que a criança ocupa nas relações sociais é condicionado pelas concepções de infância e criança, entendê-la como sujeito é fundamental. Entretanto, a infância enquanto período da vida que o sujeito não precisa produzir por sua sobrevivência "não foi ainda consolidado e não o será senão também pela luta contra a concentração de riqueza, saber e poder" (MELO, 2007, p. 84).

Não temos a pretensão de romantizar ou enrijecer quem são esses sujeitos de pouca idade, mas reconhecê-los como seres que vivem o contexto da luta pela terra, pela Reforma Agrária Popular, pela garantia de direitos básicos e, sobretudo, pela superação da sociedade vigente e o acesso a uma formação plena. Em algumas situações, pudemos identificar elementos expostos pelas crianças que representam a pertença pela luta, pelo MST. Durante uma atividade em sala, enquanto todos estavam em silêncio escrevendo, Ernesto (nove anos) começa a cantar palavras de ordem, rapidamente, muitos o acompanham com os braços erguidos, voz alta e o sorriso no rosto.

As palavras se modificam e chamam nossa atenção: "eu tô boladão, não vou deixar o

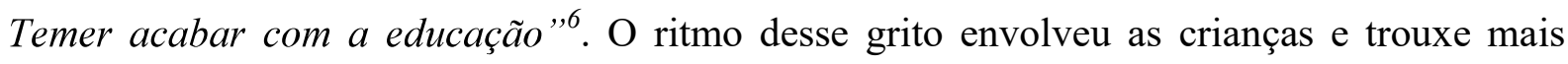
empolgação para esse momento. Após algum tempo, a professora solicita a Ernesto - por ter sido o responsável pela movimentação - que encerre para voltarem a fazer a atividade anterior. Ele pede à turma, todos param e retornam ao que estavam fazendo. Entendemos que a ação da professora, em não apenas permitir essa movimentação, mas participar dela, cantar os gritos de ordem juntamente com as crianças e depois encaminhar àquela que iniciou para que encerre a ação, faz parte da concepção formativa de luta do MST (CALDART, 2015).

Segundo Krupskaya (2017, p.83), a criança revolucionária não é o "bom estudante" que apenas aprende "bem as lições", permanecendo imóvel na sala de aula por medo de mover-se, mas sim "o estudante que reflete sobre o que ele estuda, ele está interessado nos

\footnotetext{
${ }^{6}$ Diário de campo, observação do $2^{\circ}$ Ano, março de 2018.
} 
estudos, entende que é necessário cuidar para que todas as condições sejam favoráveis ao ensino na classe; ele é um estudante que sabe conduzir-se na escola e fora da escola".

De acordo com a referida autora, é necessário construir a consciência proletária:

[...] há proletários que estão completamente imbuídos da ideologia burguesa, proletários que são estranhos aos ideais proletários, à disciplina proletária e à firmeza. É pouco ter uma origem proletária - o proletariado deve entender ainda suas tarefas de classe, deve elaborar para si a consciência de classe. (KRUPSKAYA, 2017, p.101)

Kruspakaya (2017, p. 83) alerta-nos que o importante não são as frases prontas que as crianças reproduzem, mas os valores que são construídos; não apenas fazer as crianças ouvirem e repetirem, mas como torná-las seres humanos com valores da classe trabalhadora. Ou seja, a educação proletária precisa ser construída por meio da consciência de classe. Nesse sentido, enfatiza que antes das crianças serem ensinadas pela forma proletária (em questões ligadas à técnica, à história de classe, à eloquência etc.), "elas precisam ser educadas proletariamente.".

Nessa perspectiva, compreendemos que a vida no acampamento, no seio da luta, potencializa a formação dos sujeitos Sem Terrinha da classe trabalhadora.

[...] a pedagogia proletária não parte de duas datas abstratas, mas de uma concreta. A criança proletária nasce dentro de sua classe. Mais exatamente, dentro da prole de sua classe, e não no seio da família. Desde o início ela é um elemento dessa prole, e aquilo que ela deve tornar-se não é determinado por nenhuma meta educacional doutrinária, mas sim pela situação de classe. Esta situação penetra-a desde o primeiro instante, já no ventre materno, como a própria vida, e o contato com ela está inteiramente direcionado no sentido de aguçar desde cedo, na escola da necessidade e do sofrimento, sua consciência. "Esta transforma-se então em consciência de classe. Pois a família proletária não é para a criança melhor proteção contra uma compreensão cortante do social do que seu puído casaco de verão contra o cortante vento invernal". (BENJAMIN, 1984, p. 90, grifo nosso).

Isto posto, compreendemos a criança a partir de seu contexto de classe. Nesse sentido, destacamos a movimentação das crianças em relação a ordem de despejo que havia sido recebida há poucos meses no acampamento ${ }^{7}$, observando como elas realmente fazem parte dessa luta pela terra. As crianças ajudaram a organizar barricadas, participaram das manifestações, construíram cartazes, gritos de ordem, etc. Não são apenas "coadjuvantes", mas participam, interferem e são afetadas por essas questões. Portanto, a identidade dos Sem

\footnotetext{
7 De acordo com Carignano (2017), em outubro de 2017, os Sem Terra receberam ameaça de despejo do Supremo Tribunal de Justiça (STJ) para reintegração de posse da área.
} 
Terrinha é construída também por meio da luta de classes. É na experiência da luta que se constrói a consciência, a politização, a concepção de mundo, "isso não pode ser criado por nenhum livro, isso se faz pela experiência, pela prática da luta. Mas é necessário expandir, consolidar, aprofundar, sistematizar isso. Um livro, um filme, o rádio ajudam e devem ajudar aqui. Mas o principal é a experiência." (SHULGIN, 2015, p.183).

As crianças percebem que o fato de terem uma escola no acampamento, próxima às suas casas, além de permitir uma articulação maior entre o trabalho pedagógico, a realidade e a experiência de vida dos acampados, possibilita que os estudos não sejam interrompidos, nem prejudicados como acontece de forma cada vez mais frequente com escolas rurais por meio da nucleação ${ }^{8}$. Algumas crianças contam ${ }^{9}$ as histórias dos acampados antes da Escola Itinerante Caminhos do Saber ser construída, quando as crianças precisavam ser transportadas por um caminhão-baú, falam dos acidentes, do perigo, narram a conquista dos acampados, apesar de não serem nascidos naquela época.

Nessa discussão, Ernesto (nove anos) afirma enfaticamente "eu não ia poder estudar" se não houvesse escola no acampamento. Outras crianças concordam com ele, demonstrando que percebem a importância da Escola Itinerante em suas vidas. Além disso, nas entrevistas, tanto as crianças quanto os coordenadores dos NS, referiram-se ao fato de morar perto da escola, de não precisar faltar por conta da chuva, das péssimas condições da estrada ou da distância como pontos positivos em relação a escola pesquisada. Observamos, com isso, que as crianças se entendem enquanto sujeitos que necessitam ter direitos garantidos para além de sua sobrevivência.

Percebemos, pelas falas e ações das crianças, a ideia do ser humano como sujeito histórico. Exemplificamos com a frase de Simon (10 anos), ao explicar o que significa o vermelho na bandeira do MST "é o sangue dos que lutaram e tombaram por nós" ${ }^{10}$. Isto significa entender que há pessoas hoje que se organizam para conquistar seus direitos, mas que muitos deles já foram conquistados anteriormente por outras, e que a luta de hoje pode não os beneficiar diretamente, mas beneficiará os próximos que virão.

Uma das características das escolas do MST, bem como das escolas-comunas, é formar o sujeito revolucionário, lutador, construtor de uma nova sociedade. Para isso, é preciso construir valores e habilidades em todos, desde a mais tenra idade. Alguns dos elementos para a auto-organização é a disciplina, a responsabilidade, o comprometimento.

\footnotetext{
${ }^{8}$ Compreendemos esse processo como "unificação ou reunião de estabelecimentos escolares numa única escola núcleo, resultando no fechamento das demais" (PEIXER; VARELA, 2016).

${ }^{9}$ Houve essa discussão na aula do $2^{\circ}$ Ano durante a realização da nossa pesquisa.

${ }^{10}$ Diário de campo, observação do $5^{\circ}$ Ano, março de 2018.
} 
Entretanto, salientamos que percebemos não apenas a criança e sua natureza infantil, mas sobretudo, a situação de classe desses sujeitos, "situação essa que jamais constitui um problema real para o "reformador escolar"' (BENJAMIN, 1984, p. 90). Portanto, enfatizamos a necessidade de formar as crianças com os princípios coletivos, da classe trabalhadora, partindo de uma visão crítica do trabalho e das relações estabelecidas por meio do capital fortalecendo, assim, a luta dos trabalhadores. É ilusório pensarmos numa revolução social, política e econômica, se não considerarmos a organização coletiva da classe trabalhadora. Formar sujeitos individualistas é o que a sociedade capitalista vêm fazendo com êxito. Nossa proposta emancipatória precisa ir contra essa lógica de formação humana.

Assim, corroboramos com Shulgin (2015) em defender a criação de novos comportamentos e personalidades para as crianças. O compromisso da Pedagogia Socialista pauta-se na responsabilidade da aquisição dos conhecimentos produzidos historicamente pela humanidade. Vygostky (2001) afirma que a principal função da aprendizagem escolar é refletir na personalidade do sujeito, incidindo em sua maneira de ser e agir no mundo. Uma educação que se preocupe com o conteúdo, mas que tenha em vista os objetivos formativos emancipatórios; uma educação que almeja a formação de crianças capazes de se autoorganizarem, de compreender e reivindicarem seus direitos perante uma sociedade de classes.

\section{O ESTUDO, A BRINCADEIRA E A RELAÇÃO COM OS PROFISSIONAIS DA ESCOLA}

Em relação ao estudo, podemos perceber pela fala de Blanca (nove anos), a qual foi corroborada por seu colega durante nossa entrevista, o interesse pelo aprendizado: "tinha dias que a gente não queria brincar, a gente queria estudar, mas ela deixava a gente só brincando" ${ }^{, 11}$, referindo-se à professora do ano anterior.

As crianças do $2^{\circ}$ Ano observadas estavam se apropriando do conhecimento da leitura e da escrita, enquanto as crianças do $5^{\circ}$ Ano já eram alfabetizadas e a maioria letrada. Sem a pretensão de entrarmos nessa discussão acerca da alfabetização e do letramento, mas na busca de afirmar como essa organização escolar, a qual parte da realidade e busca desenvolver outras dimensões humanas, também é capaz de ensinar os conteúdos e aprendizados escolares. Ler e escrever, numa sociedade desigual, torna-se um ato revolucionário para a população pobre do Brasil, historicamente destinada ao analfabetismo, à fome e à exploração.

\footnotetext{
${ }^{11}$ Entrevista com crianças estudantes do $3^{\circ}$ Ano. Pesquisa de Campo, março de 2018.
} 
Ainda que seja importante refletir acerca da disciplina necessária que as crianças precisam adquirir para o estudo, para se organizarem, para vivenciarem a coletividade, vale destacarmos que estas crianças também brincam, desenvolvem sua imaginação, têm seus momentos de fruição. Seus movimentos não são apenas ditados por regras ou impostos pelos adultos, também são livres, autônomos e criativos. Isto é, a criança aprende a ter disciplina, mas isso não significa que ela deixa de ser criança, deixa de vivenciar sua infância por conta de uma "rigidez" ou "autoritarismo" impostos pela necessidade da luta. O MST já demonstra sua preocupação com a infância desde que começou a organizar as Cirandas Infantis e a lutar por escolas dentro dos acampamentos e assentamentos da Reforma Agrária.

O estudo e a brincadeira aparecem em outras falas infantis como algo que se complementam, que estão interligados.

\footnotetext{
Pesquisadora: O que vocês acham mais legal nessa escola?

Ernesto (nove anos): jogar bola, escrever, ter educação física, a professora ajuda nós. Dai também nós faz bagunça, dai a professora deixa nós ir pro recreio e de vez em quando ela deixa nós brincar quando tá sol, e de vez em quando nós desce lá embaixo para jogar bola. (Entrevista com crianças estudantes do $2^{\circ}$ Ano. Pesquisa de Campo, março de 2018).
}

A sala de aula mostra-se como um lugar em que as crianças também veem a possibilidade de brincar, diferentemente da crítica que Quinteiro (2000) faz sobre a inserção da criança na escola pública capitalista por ter sua identidade infantil transformada e minimizada unicamente em "aluno", uma vez que perde algumas de suas possibilidades de ações infantis. Isso evidencia o quanto a escola do MST tem avançado em relação ao papel da educação na formação humana respeitando as necessidades das crianças e sua possível emancipação.

Todas as crianças entrevistadas responderam que uma das coisas que mais gostam na escola é poder brincar. Olga (10 anos) afirma que um dos pontos positivos da escola são "os colegas daqui, lá a gente não tinha muitos colegas, aqui pode ser de qualquer série, pode ser do $6^{\circ}$ que é amigo do $4^{\circ}$, lá só tinha só da sala da gente mesmo, que era amigo da gente",12. Com isso, compreendemos que a escola apresenta-se também como um espaço de brincadeira e de socialização para as crianças e demais estudantes.

Dentro da sala, as crianças observadas não permanecem apenas sentadas durante a aula, circulam pelo ambiente, trocam de lugares, vão até a mesa dos colegas, conversam, cantam, sentam no chão em frente ao quadro (para visualizarem melhor) e ambos os

\footnotetext{
${ }^{12}$ Entrevista com crianças estudantes do $5^{\circ}$ Ano. Pesquisa de Campo, março de 2018.
} 
professores não se importam com essa movimentação ${ }^{13}$. Apenas na hora das explicações era solicitado silêncio e atenção, mas no decorrer das atividades, as crianças não precisavam ficar imóveis. Houve momentos que crianças de outras turmas entravam na sala, observavam por um tempo e saiam, numa constante interação entre diferentes grupos e idades.

Além disso, houve diversas situações em que os sentimentos de solidariedade e de companheirismo se destacaram nas relações entre as crianças. Krupskaya (2017) enfatiza a importância de construir desde cedo o sentimento de "camaradagem", educar as crianças, filhas dos(as) trabalhadores(as) para serem solidárias. Destacamos algumas dessas situações: várias crianças no $2^{\circ}$ Ano pediam a borracha emprestada para Constance (sete anos), a resposta dela era a mesma "não precisa nem pedir"; uma criança do $5^{\circ}$ Ano aprende o conteúdo e rapidamente compartilha com seus colegas; um menino reclama que não pode escrever porque está sem lápis, prontamente Anita (sete anos) se levanta e empresta um a ele, "pode pegar, eu tenho dois"; uma menina mostra atividade incompleta para professora, Ernesto (nove anos) imediatamente vai ajudá-la a terminar; um menino sentado no chão em frente ao quadro soletra em voz alta para a colega conseguir escrever, pois a mesma não estava conseguindo enxergar o quadro; Anita (sete anos) se perde ao copiar do quadro, Vilma (sete anos) leva seu caderno até a frente para conseguir achar o lugar que ela parou (Diário de Campo, observação nas turmas, março de 2018).

Chamamos atenção para esses momentos, pois nenhum deles foi direcionado pelos adultos, todos partiram das crianças em resolvê-los. Ao tomarem as iniciativas rapidamente e resolver as situações com tranquilidade, nos pareceu fazer parte da cultura das crianças a partilha e a solidariedade entre pares. Entretanto, os/as professores(as) ao percebê-los demonstraram satisfação, como se realmente fosse algo que estivesse em construção nas crianças, isto é, são aprendizados que elas estão conseguindo internalizar e praticar e que possuem como base o meio social e a cultura em que estão inseridas.

Essa relação entre os profissionais e as crianças nos pareceu de confiança e cumplicidade. As crianças dos Anos Iniciais entrevistadas enfatizaram a ideia de que com os adultos é possível estabelecer diálogos, respeito, atenção em suas falas, "só as professora escutava e os adulto" "14 afirmaram. Ao comparar a Escola Itinerante com outra escola que

\footnotetext{
${ }^{13}$ Salientamos que por conta da iluminação da sala e das condições do quadro, era difícil visualizar o que estava escrito, assim, as crianças movimentavam-se com frequência pela sala para acharem um lugar melhor para enxergar, por vezes ficavam em pé apoiadas na janela. Esse é um dos reflexos da precarização das Escolas Itinerantes, as quais representam o descaso do Estado e a necessidade de organização do MST, o qual, por meio do Setor de Educação do Acampamento, é quem se responsabiliza pela manutenção da infraestrutura.

${ }^{14}$ Ernesto, nove anos. Pesquisa de Campo, março de 2018.
} 
havia estudado, Anita (sete anos) afirma que além de não haver Tempo Formatura e Núcleo Setorial, "não tinha professora que escutava nós, não tinha professora legal”. Quando se referiam à relação estabelecida com os professores, apresentavam dois principais elementos para justificar o gosto, a proximidade e o respeito, sendo eles: o ensino e a escuta. As crianças e os demais estudantes relacionavam a forma como os professores explicavam, a maneira como o ensino era trabalhado e como o que fora apreendido era significativo. Além disso, uma das primeiras questões que abordavam era o fato dos adultos permitirem que as crianças falassem e realmente as escutassem.

Nesse sentido, o processo de aprendizagem para as crianças está intimamente ligado ao ensino, especialmente no que compõe a relação com os professores, como podemos perceber nesses fragmentos das entrevistas com os estudantes:

Sophie (oito anos): Eu gosto da professora Joelia, eu amo ela. A partir de que ela me ensinou a escrever letra de mão, eu amo ela.

Martin (sete anos): Eu lembro do primeiro dia que a Joelia ensinou a gente a escrever com letra de mão, a primeira letra que ela escreveu lá eu lembro qual que $e ́$, foi a primeira letra do meu nome, o 'e' minúsculo e o 'e' maiúsculo. (Entrevista com crianças estudantes do $3^{\circ}$ Ano. Pesquisa de Campo, março de 2018).

Emiliano (13 anos): Lá os professores era mais rígido e a maioria dos alunos eram só pra aprendimentos né, só conteúdo, ai a gente achava o professor muito chato $e$ dizia 'não vou fazer nada'. Aqui já é diferente, aqui você não entendeu alguma coisa, eles vem e te explico até precisar, é muito legal aqui, lá é só uma vez, no $2^{\circ}$ ano eu pedi ajuda pra uma professora e ela chegou a me chamar de burro, eu pedi pra ela me explicar um conteúdo, aqui não, eles tão focados no meu aprendizado.

Haydee (12 anos) era bem diferente, eles eram mais rígidos, já aqui tem uns professor que gosta de dar carinho. Os professores daqui eles são mais abertos, eles tem liberdade pra conversar com os alunos, tipo puxar brincadeiras, e já nessas escolas de cidade que eu já participei elas são diferentes. Ela tem os professores mais rígido, eles tem caras fechadas, estranhos, sei lá. [...] a gente conversa sobre a vida da gente, o que que tá acontecendo, eles contam também. Daí a gente tem tipo contato com o professor e ele tem contato com o aluno, tipo assim na cidade, o aluno pode tá passando por uma fase difícil, o professor não tem aquele contato, já aqui eu já vi várias vezes o aluno ficar triste, chorar e o professor ajudar.

Emiliano (13 anos): lá na cidade o professor nem tem o contato com o aluno de professor mesmo, aqui tem uma certa amizade muito grande com os professores. (Entrevista com coordenadores dos NS. Pesquisa de Campo, março de 2018).

Simon (10 anos): Aqui a gente pode perguntar se tem alguma dúvida, 'o professor como é isso aqui', daí ele explica, ele ajuda a gente; ele não briga; se a gente não entendeu 10 vezes ele explica 10 vezes até a gente entender!’. (Entrevista com crianças estudantes do $5^{\circ}$ Ano. Pesquisa de Campo, março de 2018).

Constantemente, os(as) professores(as) das turmas observadas trabalharam valores como respeito, companheirismo, compartilhamento e responsabilidade. Não apenas falavam sobre esses temas, mas buscavam situações em que pudessem ser ensinados e aprendidos, seja por meio de histórias, brincadeiras, atividades, jogos ou momentos rotineiros práticos para o 
exercício. Os diálogos dos professores com as crianças eram baseados no respeito, tinham sua autoridade enquanto educadores, mas esta não se engendrava num autoritarismo, encaminhavam os combinados, as regras, os valores por meio do diálogo, com explicações e não imposições. Em diversos momentos, lembravam do cuidado necessário com o bem público, do respeito ao próximo, de ajudar o colega, ser companheiro.

O respeito é ensinado na prática, se as crianças precisam aprender a respeitar, devem fazer isso enquanto estão sendo respeitadas. Como afirma Freitas (1995), não podemos alcançar um produto não alienado, se o processo for alienante. Referente a isso, apresentamos a situação em que a professora do $2^{\circ}$ Ano entende o medo de um menino quando ele não consegue copiar o quadro por ela ter apagado, e chora. Ela não minimiza esse medo. Resolve a situação, escrevendo para a família o que houve.

Isso não significa que as crianças não precisam seguir os encaminhamentos dos professores para as atividades ou comportamentos em sala e fazerem apenas o que quiserem. Houve uma situação no $2^{\circ}$ Ano, em que a atividade consistia em realizar um desenho e Ernesto (nove anos) afirma que vai escrever ao invés de desenhar. A professora explica a ele que o encaminhamento é outro e que não podemos fazer apenas o que temos vontade, uma vez que precisamos saber quando respeitar, quando realizar os encaminhamentos que foram dados, pois somente assim as pessoas também respeitarão seus encaminhamentos. Pistrak (2011) aborda essa questão explicando que as crianças precisavam ocupar cargos de dirigentes e subordinados entre seus coletivos para desenvolver tais habilidades. Há momentos em que precisam direcionar a ação e outros em que precisam saber ser direcionados. Ainda, afirma que não devemos atender todas as vontades infantis, pois "senão estaríamos indo a reboque das preocupações acidentais das crianças. E essa forma seria nefasta, porque estimularia os piores instintos das crianças, exatamente os que não fortalecem absolutamente o coletivo infantil" (PISTRAK, 2011, p.159).

Em diversos momentos foi observado encaminhamentos sobre disciplina para a aprendizagem, respeito e responsabilidade. Tanto os profissionais quanto as próprias crianças explicavam e cobravam isso de seus colegas para que fosse possível vivenciar o cotidiano escolar. A ideia da disciplina é construída, mas não imposta. É explicado o seu valor, a sua responsabilidade perante essa sociedade de classes em que os trabalhadores precisam ter disciplina para alcançar seus objetivos, uma vez que seus direitos, historicamente, precisam ser conquistados. Com base em Krupskaya (2017, p. 115), a auto-organização é uma "forma de ensinar a autodisciplina, como hábito para acatar voluntariamente a vontade coletiva". 
Não há uma inflexibilidade nos comandos da escola. Não é por ser baseada numa pedagogia revolucionária que não é capaz de pensar a criança enquanto criança, nem tampouco, de estabelecer ordens e achar que só por elas existirem, todos a respeitarão e a cumprirão em todos os instantes. Claramente, os adultos envolvidos nesse processo têm esse pensamento bastante fortalecido e buscam, em sua prática diária, lembrar dele ao lidar com as crianças e os demais estudantes.

Na escola há, efetivamente, a distinção entre professor(a) e estudante, no sentido de ambos perceberem suas responsabilidades específicas, tendo em vista a responsabilidade do outro. Isto é, professores(as) ensinam não apenas por ensinarem, por realizarem sua tarefa enquanto educadores(as), mas ensinam pensando realmente se os estudantes estão aprendendo. A relação entre ensino-aprendizagem parece realmente ser incorporada por eles. As crianças, por sua vez, demonstram que seu aprendizado está relacionado à forma como é ensinado, tanto em relação à organização da escola, quanto ao ensino realizado pelos profissionais.

A aula é o momento em que o(a) professor(a) é responsável, mas isso não significa que as crianças não participem desse momento também. $O$ fato deles estabelecerem relação harmoniosa e respeitosa com as crianças, de pedirem suas opiniões, de explicarem ao invés de decretarem, é uma forma de permitirem a participação infantil na sala de aula. As crianças não podem fazer tudo ou somente o que querem, porque essa não é a proposta da escola, nem tampouco a concepção de auto-organização na qual está ancorada, mas ajudá-las a pensar no que querem e em formas de conquistarem, é uma das tarefas que os(as) professores(as) se propõem a realizarem. Esse movimento não é natural, é construído por meio da organização da prática pedagógica. São ensinamentos constantes para as crianças e para os professores e, dessa forma, as crianças crescem inseridas numa cultura de respeito, solidariedade, engajamento e democracia.

\section{PARTICIPAÇÃO INFANTIL E CAMINHOS PARA A FORMAÇÃO SOCIALISTA DAS CRIANÇAS}

Ao partir da teoria Histórico-Cultural, a qual defende a dialética entre aprendizagem e desenvolvimento, compreendemos a necessidade de possibilitar condições de múltiplas aprendizagens e vivências para as crianças, contrapondo-se aos conhecimentos isolados, fragmentados e pontuais. O compromisso dessa teoria é com o ser humano em suas diversas 
dimensões, as quais são capazes de possibilitarem mudanças significativas no desenvolvimento humano.

Segundo Freitas (1995), a formação democrática de trabalho, com base na efetiva participação estudantil na escola, contribui para formar um sujeito democrático que lute por uma organização social democrática. Assim, com o objetivo de compreender como as crianças entendem suas participações e o que a escola representa para elas e para os profissionais atuantes, questionamos sobre os aspectos que a diferenciam das outras escolas que já conheceram, estudaram ou trabalharam. Com isso, percebemos que a maneira como a Escola Itinerante é organizada, como entende o conhecimento humano, como enxerga as crianças e seu desenvolvimento é positivamente interpretada por elas.

O conhecimento não é apenas reproduzido, imutável, inerte, ele está em constante construção e as crianças participam disso. Em contraponto a ideia da pedagogia burguesa que vê a criança apenas como alguém capaz de aprender, a concepção educacional socialista entende esse ser humano com sua capacidade de criação, produção, invenção, onde a liberdade, a autonomia e a autogestão são partes importantes do processo criativo:

Simon (10 anos): Aqui a gente escolhe o que vamo fazer. (Entrevista com crianças estudantes do $5^{\circ}$ Ano. Pesquisa de Campo, março de 2018).

Ernesto (nove anos): Porque tem que fazer chamada, pensar o grito de ordem, é legal também por causa que a gente fala na Reunião Executiva, depois passa pro setor e faz. (Entrevista com crianças estudantes do $2^{\circ}$ Ano. Pesquisa de Campo, março de 2018).

Blanca (nove anos): Assim oh nós tava trabalhando dai na hora que bateu o sinal que era pra ir pro recreio, não antes de bater, quase um pouquinho antes, nós arrancamos um monte de rúcula, rabanete e ponhamos tudo numa bacia, a Marli colocou na bacia, dai nós levamos ali na janelinha da cozinha, ponhamos, dai ela lavou, dai nós voltamos pra lá, veio pro recreio e comemos rabanete e rúcula da nossa própria produção. (Entrevista com crianças estudantes do $4^{\circ}$ Ano. Pesquisa de Campo, março de 2018).

Evidenciamos a satisfação presente nas falas das crianças ao narrarem sobre algo que tinham produzido ou participado, como na construção dos gritos de ordem, nas propostas de encaminhamentos sobre a estrutura da escola, nas atividades das aulas, nos trabalhos dos Núcleos. Ernesto (nove anos) fala com entusiasmo "aquela música lá foi eu que inventei". Anita (sete anos) complementa "eu falei da tábua e do ventilador no Núcleo e arrumaram. Do nosso grupo foi eu que pensei o grito de ordem" (Entrevista com crianças estudantes do $2^{\circ}$ Ano. Pesquisa de Campo, março de 2018). 
As crianças são informadas sobre questões pertinentes à organização da instituição ${ }^{15} \mathrm{e}$ afirmam que contribuem com a construção dos encaminhamentos pedagógicos. Além de participarem dos processos avaliativos constantemente, produzem conhecimento. Em suas palavras:

\begin{abstract}
Simon (10 anos) Lá a gente tinha que cantar o hino do Brasil, aqui não, aqui a gente faz uma mística, apresenta nosso hino que nós que inventemo e o nosso hino do acampamento.

Olga (10 anos): Lá a gente tinha um grito, assim que a gente entrava na sala a gente fazia nosso grito, mas a gente não escolhia o grito que ia fazer, a professora que escolhia, aqui não, aqui a gente, lá no Núcleo, a gente mesmo escolhe nosso grito, igual aquela vez lá que eu ajudei a escolher o grito. [...]Eu gosto de uma coisa daqui que eu não gostava lá, eu gosto de participar das coisa, de participar de poder fazer alguma coisa, tipo se alguém me perguntava 'quem quer fazer o teatro?', daí eu não gostava do papel que tinha que fazer. Aqui não, aqui a gente pode escolher o que quer fazer. Lá a professora falava 'você vai ser a malvada ou vai ser a feiticeira', daí eu tinha que ser e eu nunca gostava de fazer, aqui eu gosto, eu escolho. (Entrevista com crianças estudantes do $5^{\circ}$ Ano. Pesquisa de campo, março de 2018).
\end{abstract}

Todos esses elementos permitem que as crianças se sintam pertencentes à escola, responsáveis por seus processos de aprendizagem, capazes de contribuir com os processos de ensino e interessadas em se envolverem nos processos pedagógicos. Assim, percebemos como esse lugar é significativo para elas, como é um espaço em que valores e comportamentos são construídos, ensinados e socializados.

No contexto escolar, percebemos que há o cuidado com a individualidade das crianças, desde respeitá-las até potencializá-las. Olhando para as interações, para o comportamento, para apreensão do conhecimento e para o desenvolvimento das personalidades de cada sujeito. Evidenciamos esse olhar dos profissionais, enxergando cada criança com base em seu processo individual de aprendizagem e desenvolvimento.

\title{
CONSIDERAÇÕES FINAIS
}

Diante desse cenário, compreendemos a participação das crianças como imprescindível no processo de auto-organização dentro da escola, o qual pode possibilitar a aprendizagem da auto-gestão social. Ao pensarmos na participação como um elemento importante para a formação humana, que possibilita a atividade criadora do ser humano com sua capacidade de transformação, nos remetemos a Vygotsky (2009) ao afirmar que a atividade humana não é caracterizada unicamente pela repetição do que já existe, pois assim, seríamos homens, "voltado(s) somente ao passado, adaptando-se ao futuro apenas na medida

\footnotetext{
${ }^{15}$ Professora do $2^{\mathrm{o}}$ Ano avisa a turma que duas acampadas passaram a entregar os alimentos para a escola. A maioria das crianças comemora essa informação, como se entendessem a conquista que há por trás dessa ação.
} 
em que esse reproduzisse aquele. É exatamente a atividade criadora que faz do homem um ser que se volta para o futuro, eregindo-o e modificando seu presente" (VYGOTSKY, 2009, p. 14).

Isto posto, inferimos que o fato da criança poder participar, opinar, decidir, falar e ser ouvida é fundamental para o processo de aprendizagem e desenvolvimento que comunguem com a formação do sujeito revolucionário, construtor de uma outra sociedade. Segundo Krupskaya (2017, p. 122), "a auto-organização para ter efeito educativo, influenciar a disciplina das crianças, deve ser compreendida por elas como algo necessário, que decorre de uma dada necessidade", ou seja, tem que fazer sentido e ser uma atividade. Isso significa que a participação da criança é fundamental no processo de aprendizagem da auto-organização: “a educação coletivista deve estar ligada com a educação multilateral do desenvolvimento da pessoa internamente disciplinada, capaz de sentir profundamente, de pensar com clareza e agir de forma organizada" (KRUPSKAYA, 2017, p.141).

Assim, compreendemos que são criadas novas internalizações nas crianças por meio das novas relações construídas pela escola, isto é, as personalidades infantis são formadas com base nos ensinamentos e espaços formativos. Ao afirmarmos que as crianças têm voz garantida na escola, que participam de tomadas de decisões e ajudam na organização da instituição, demonstramos que há outras formas de conduzir as relações entre adultos e crianças dentro desse espaço educativo. Nessa instituição há conflitos, dilemas, contradições, momentos caóticos nas aulas, nos espaços dos Núcleos, mas também há formas diferentes de lidar com o outro, de respeitar as singularidades infantis, de se importar e de se impor. A coordenadora $\mathrm{C} 1$, enfatiza que, ainda que as falas das crianças precisem ser "lapidadas", no sentido de ultrapassar as narrativas agressivas e desrespeitosas, é preciso garantir que as crianças falem e se manifestem, pois somente na prática as críticas vão se aperfeiçoando.

Ao defendermos que a escola da classe trabalhadora precisa superar a lógica do individualismo, da propriedade privada, por meio do espírito coletivo, ensinando a criança perceber-se como um ser único que faz parte de um todo, inferimos que a experiência da Escola Itinerante Caminhos do Saber, está nesse caminho. Sobretudo, afirmamos que não existe apenas um elemento na escola capaz de contribuir com o desenvolvimento de uma identidade infantil auto-organizada, mas sim que toda a organização do trabalho pedagógico caminha para a formação socialista das crianças.

Concluímos que as crianças e os demais estudantes ainda não se auto-organizam, mas aprendem e desenvolvem habilidades, comportamentos, valores e hábitos de organização, fundamentados em princípios socialistas. Sobretudo, evidenciamos a prática dos Núcleos 
Setoriais como um ensaio coletivo da auto-organização que a escola almeja alcançar, percebendo-o como um espaço potencializador para o desenvolvimento dessa prática.

\section{REFERÊNCIAS BIBLIOGRÁFICAS}

BENJAMIN, W. Reflexões: A criança, o brinquedo, a educação. São Paulo: Summus, 1984.

CAMINI, I.; RIBEIRO, M. Escola itinerante: onde escola, luta e vida se entrecruzam. In: VENDRAMINI, Célia Regina e MACHADO, Ilma Ferreira (Orgs.). Escola e movimento social: 320 experiências em curso no campo brasileiro. São Paulo: Expressão Popular, 2011.

CARIGNANO, J. Ameaça de despejo mobiliza 430 famílias do MST no norte do Paraná: Enquanto luta por assentamento, comunidade Maila Sabrina cultiva área de 7 mil hectares. 2017. Disponivel em: http://porem.net/2017/10/31/ameaca-de-despejo-mobiliza430-familiasdo-mst-no-norte-do-parana/ Acesso em: 01/03/2018.

FREITAS, Luiz Carlos de. A luta por uma pedagogia do meio: revisitando o conceito. In:

MAKARENKO, A. Os objetivos da educação; Metodologia para a organização do processo educativo; A família e a educação dos filhos. In: LUEDEMANN, C. da S. Anton Makarenko: Vida e obra- a pedagogia na revolução. São Paulo: Expressão Popular, 2002.

MELLO, Suely Amaral de. O lugar da criança na pesquisa sobre a infância: alguns posicionamentos na perspectiva da teoria histórico-cultural. Reflexão e Ação, 2010, v. 18, no 2, p. 183-197. Disponível em: $<$ http://www.klcconcursos.com.br/apoio/eac9965cdf8d1185b8adaf482804a425.pdf.> Acesso em 11/07/2016.

MESZÁROS, István. Educação para além do capital. Tradução de Isa Tavares. São Paulo: Boitempo, 2005.

KRUPSKAYA, Nadezhda K. A construção da Pedagogia Socialista. São Paulo: Expressão Popular, 2017.

PISTRAK, Moisey (Org.). A escola-comuna. São Paulo: Expressão Popular, 2009.

PISTRAK, Moisey M. A Escola-Comuna; tradução de Luiz Carlos de Freitas e Alexandra Marenich. São Paulo: Expressão Popular, 2009.

PISTRAK, Moisey M. Fundamentos da escola do trabalho; tradução de Daniel Aarão Reis Filho. 3 ed. São Paulo: Expressão Popular, 2011.

PISTRAK, Moisey. Ensaios sobre a escola politécnica. São Paulo: Expressão Popular, 2015.

QUINTEIRO, J. Infância e escola: uma relação marcada por preconceitos. (tese). São Paulo, 2000. 
SARMENTO, Manuel Jacinto; PINTO, Manuel. As crianças e a infância: definindo conceitos, delimitando o campo. In: PINTO, Manuel; SARMENTO, Manuel Jacinto. As crianças: contextos e identidades. Portugal, Centro de Estudos da Criança: Ed. Bezerra, 1997.

SHULGIN, Viktor N. Rumo ao politecnismo. São Paulo: Expressão Popular, 2013.

Recebido em 23.02.2019

Aprovado em 07.04.2019 